\title{
Anterior Abdominal Wall Muscle
}

National Cancer Institute

\section{Source}

National Cancer Institute. Anterior Abdominal Wall Muscle. NCI Thesaurus. Code C52890.

A muscle located in the anterior aspect of the abdominal wall. 